\title{
Effects of meloxicam on milk production, behavior, and feed intake in dairy cows following assisted calving
}

\author{
Nathalie C. Newby, ${ }^{*}$ David L. Pearl, ${ }^{*}$ Stephen J. LeBlanc, ${ }^{*}$ Ken E. Leslie, ${ }^{*}$ Marina A. G. von Keyserlingk, $\dagger$ \\ and Todd F. Duffield*1 \\ *Department of Population Medicine, University of Guelph, Guelph, Ontario N1G 2W1, Canada \\ †Animal Welfare Program, University of British Columbia, Vancouver, British Columbia V6T 1Z4, Canada
}

\begin{abstract}
Parturition is a necessary event for production in dairy cattle, and assistance at calving is common. There is limited use of nonsteroidal antiinflammatory drugs for the alleviation of calving pain and a paucity of research on the effects of these drugs on postpartum health and performance. This randomized triple blind clinical trial involved Holstein cows $(\mathrm{n}=42)$ and heifers $(\mathrm{n}=61)$ that experienced an assisted parturition. These animals received either 1 injection of meloxicam ( $0.5 \mathrm{mg} / \mathrm{kg}$ of body weight) or placebo subcutaneously $24 \mathrm{~h}$ following calving. Outcome measures included dry matter intake (DMI) and milk production for the first $14 \mathrm{~d}$ in milk, blood metabolites sampled over $12 \mathrm{~d}$, health events for the first $60 \mathrm{~d}$ in milk, as well as lying and feeding behavior $24 \mathrm{~h}$ following injection. Continuous data were analyzed using multivariable regression models. Binary outcomes were analyzed using a mixed logistic model with cow modeled using a random intercept. This study failed to show any significant effects of treatment on DMI, milk production, blood metabolites, or health events. A possible explanation for the lack of treatment differences could be that the meloxicam was administered too late after calving. Meloxicam increased feeding time as well as bunk visit frequency in the $24 \mathrm{~h}$ following injection. Regardless of treatment, animals that had retained fetal membranes produced less milk and had higher serum haptoglobin concentrations. Future research is warranted to examine the effects of antiinflammatory drugs administered closer to the time of calving on health and production.
\end{abstract}

Key words: nonsteroidal antiinflammatory drug, dystocia, pain, welfare

Received September 28, 2012.

Accepted February 22, 2013.

${ }^{1}$ Corresponding author email: tduffiel@uoguelph.ca

\section{INTRODUCTION}

Parturition is necessary for dairy production and assisted calving is common. Calving is a painful event that leads to inflammation (Bionaz et al., 2007). Dystocia rates are higher in North America $(>10 \%)$ compared with other parts of the world $(<5 \%)$, and, regardless of country, are much higher in primiparous animals (Mee, 2008). Severe dystocia (i.e., cases requiring either heavy tractive force with a calf puller, extensive corrections of malpositions, or caesarean section) was associated with reduced viability of the calf and reduced fertility and survival of the dam (Tenhagen et al., 2007). Dystocia negatively affected early lactation performance in Holstein cows, with peak yield lowered by $0.39,2.2,2.2$, and $2.5 \mathrm{~kg}$ for cows in parities 1 to 4 , respectively (Atashi et al., 2012). Dystocia is a risk factor for metritis and for purulent vaginal discharge (Dubuc et al., 2010).

In a questionnaire to cattle veterinarians in the United Kingdom, the median estimate of pain of dystocia was 7 out of 10 (Huxley and Whay, 2006). Sixty-six percent of respondents indicated using a nonsteroidal antiinflammatory drug (NSAID) in some cases of dystocia (Huxley and Whay, 2006). In a survey on analgesic use among Canadian veterinarians in 2004-2005, the mean estimate of pain level was 5.3 out of 10 (Hewson et al., 2007). Thirty-four percent of veterinarians provided analgesia to some or all cases of dystocia (Hewson et al., 2007). Despite the apparent recognition that dystocia is painful, little is known about the effects of pain resulting from difficulty or assistance at calving on production or health, or about the effects of NSAID to treat dystocia (Laven et al., 2012) and thus more work is warranted. In addition, there is a paucity of data on approaches to control this pain with medication. Insofar as we know, this is the first study to evaluate the short-term benefits of NSAID treatment following dystocia, despite the relatively common use of NSAID by veterinarians (Laven et al., 2012).

Consumption of amniotic fluid by the cow was shown to provide some analgesic effect from endogenous opioids (Pinheiro Machado et al., 1997). Current recom- 
mended management practices, such as removing the calf immediately after birth (National Farm Animal Care Council, 2009), and the relatively high incidence of dystocia likely result in many cows not being able to benefit from the ingestion of amniotic fluid. Therefore, some analgesic assistance in the form of an antiinflammatory drug may prove to be beneficial to these animals. The objective of this study was to evaluate the effect of meloxicam on behavior, health, and production in cows with assisted calving. The hypothesis was that the administration of meloxicam following assisted calving would improve feed intake and milk production and reduce inflammation and pain in dairy cows.

\section{MATERIALS AND METHODS}

\section{General Information}

This randomized controlled trial involved Holstein cows $(\mathrm{n}=42)$ and heifers $(\mathrm{n}=61)$ that experienced assisted parturition at the Elora and Ponsonby Dairy Research Centers, University of Guelph (Guelph, ON, Canada), with enrollment into the study taking place between January 2009 and January 2011. Calving difficulty was scored as follows: 1 , an easy pull by one person with no mechanical assistance, or 2 , a difficult pull with more than one person, with mechanical assistance, or a combination of both. Cows that had a fetotomy or caesarean section were excluded. Whether the animal had retained fetal membranes at $24 \mathrm{~h}$ postcalving was recorded systematically. Animals with assisted calving were blocked into primiparous and multiparous groups, and into calving difficulty, and randomly assigned within blocks to receive meloxicam $[\mathrm{n}=51 ; 0.50 \mathrm{mg} /$ $\mathrm{kg}$ of BW, Metacam $20 \mathrm{mg} / \mathrm{mL}$ solution for injection; Boehringer Ingelheim (Canada) Ltd., Burlington, ON, Canada] subcutaneously once $25.4 \mathrm{~h}$ ( $\pm 2.9 \mathrm{SD})$ following calving or to be negative controls $(\mathrm{n}=52$; injection of a similar volume of placebo (the medication vehicle solution with no active ingredient once $25.0 \mathrm{~h} \pm 2.8$ $\mathrm{SD})$. Personnel administering the treatments, recording data, and performing statistical analyses were blinded to treatment assignments.

Cows were housed in tie-stalls through the previous lactation and late gestation, and heifers were loose housed until 9 wk before expected calving when they were moved to a tie-stall. All animals were moved to individual calving pens $(7.0 \times 3.1 \mathrm{~m}$; straw pack bedding in one half and wood shavings over mattress filled with rubber crumbs in the other half) $2 \mathrm{~d}( \pm 1.8 \mathrm{SD})$ before expected calving based on their due date and appearance of early calving signs (e.g., filling of the udder). Cows remained in the maternity pen for $2 \mathrm{~d}( \pm 0.69 \mathrm{SD})$ after parturition before moving to the tie-stall for lacta- tion. All animals in both barns were fed the same TMR twice daily (0730 and $1300 \mathrm{~h}$ ) for ad libitum intake. The diet in the calving pens was composed of $1 \mathrm{~kg}$ of hay, $1.6 \mathrm{~kg}$ of haylage, $6.6 \mathrm{~kg}$ of corn silage, $0.80 \mathrm{~kg}$ of high-moisture corn, and $2 \mathrm{~kg}$ of commercial protein and mineral supplement for dry cows (DM basis: CP: $14 \%$ DM, ADF: 23-25\% DM, NDF: 35-40\% DM, fat: 3.6$3.8 \% \mathrm{DM}$, and net energy: $1.45 \mathrm{Mcal} / \mathrm{kg}$ ). The lactation diet was composed of $1.5 \mathrm{~kg}$ of hay, $6.2 \mathrm{~kg}$ of haylage, $6.2 \mathrm{~kg}$ of corn silage, $4.8 \mathrm{~kg}$ of high-moisture corn, and $5 \mathrm{~kg}$ of supplement containing soybeans, vitamin, protein, and mineral (DM basis: CP: $17 \%$ DM, ADF: 20-21\% DM, NDF: $30-35 \%$ DM, fat: $3.6-3.8 \%$ DM, and NE: $1.62-1.67 \mathrm{Mcal} / \mathrm{kg}$ ) and formulated to meet requirements (NRC, 2001) for a $650-\mathrm{kg}$ cow producing $35 \mathrm{~kg} / \mathrm{d}$ of milk at $3.8 \%$ fat. Tie-stalls had feed dividers between cows so that individual feed intakes could be measured.

\section{DMI, Milk, and BW Data}

Individual daily feed intakes were recorded from the time the cow entered the maternity pen and then in the tie-stalls until 14 DIM. Samples of the prepartum diet and the early-lactation diet were collected twice weekly and frozen at $-20^{\circ} \mathrm{C}$ for later analysis. Intake calculations were based on the amount fed to the animal, the orts recovered, and the DMI analysis of the samples. Milk yield was recorded twice daily until 14 DIM. All cows were weighed at enrollment in the study $(2 \mathrm{~d}$ before expected calving at movement into the calving pen) and at 60 DIM.

\section{Blood Collection and Analysis}

Blood samples were obtained by coccygeal venipuncture immediately after calving and 1, 3, 6, 9, and 12 DIM. The d 1 blood sample was taken at the time of treatment administration and all other blood samples were taken in the morning, approximately $3 \mathrm{~h}$ after feeding, allowed to clot for $1 \mathrm{~h}$, and centrifuged at $7,000 \times g$ (model CL international clinical centrifuge, International Equipment Co., Needham, MA) to collect the serum. Blood serum was frozen and submitted for analysis to the Animal Health Laboratory, University of Guelph. Serum was analyzed for BHBA, NEFA, glucose, calcium, and haptoglobin. All analyses were conducted using a Roche Cobas 6000 c501 automated chemistry analyzer (Roche Canada, Laval, QC, Canada). The NEFA and BHBA concentrations were determined using Randox NEFA and Randox BHBA kits (Randox Laboratories Canada Ltd., Mississauga, ON, Canada); the analytical sensitivity was $0.10 \mathrm{mmol} / \mathrm{L}$ for both assays. The inter- and intraassay coefficients of variation 
were 1.0 and $6.3 \%$, respectively, for NEFA, and 0.50 and $1.6 \%$, respectively, for BHBA. Glucose concentrations were measured using the Roche GLUC3 kit (Roche Diagnostics, Laval, QC, Canada). The analytical sensitivity of the glucose assay was $0.10 \mathrm{mmol} / \mathrm{L}$, and the inter- and intra-assay coefficients of variation were 2.9 and $2.4 \%$ respectively. Calcium concentrations were measured with a commercial kit (Roche Diagnostics). The analytical sensitivity of the calcium assay was 0.10 to $5.0 \mathrm{mmol} / \mathrm{L}$, and inter- and intraassay coefficients of variation were 2.1 and $3.3 \%$, respectively. Haptoglobin concentrations were measured by determining the hemoglobin binding capacity, using a methemoglobin reagent made on site (see Skinner et al., 1991; Skinner and Roberts, 1994). The analytical sensitivity of the haptoglobin assay was $0.03 \mathrm{~g} / \mathrm{L}$; inter- and intraassay coefficients of variation were 5.9 and $5.3 \%$, respectively.

\section{Health Events}

Rectal temperatures for the first $10 \mathrm{~d}$ postcalving were taken in the morning using a digital rectal thermometer (Digital Fever Thermometer, Omron Healthcare Inc., Vernon Hills, IL). All clinical health events and treatments were recorded for each cow enrolled in the study up to $60 \mathrm{~d}$ postcalving. Diseases of interest for their possible confounding effect included the occurrence of retained fetal membranes, milk fever, clinical mastitis, clinical ketosis [clinical signs include anorexia, depression, and positive ketone test in the milk (BHBA $\geq 100 \mu \mathrm{mol} / \mathrm{L}$ )] or urine ketone test ("small" or greater on Ketostix strips; Geishauser et al., 1998), metritis (systemic illness including fever $>39.5^{\circ} \mathrm{C}$ with fetid discharge from the vulva; LeBlanc et al., 2002), and displaced abomasum. All cows enrolled in the study were assessed for the presence of purulent vaginal discharge (PVD; Dubuc et al., 2010) once between d 30 and 36 postpartum by visual examination of the tail for purulent debris and vaginoscopy. A diagnosis of PVD was recorded if either of the 2 conditions was present.

\section{Behavior}

Feeding and lying behavior measures were collected between January 2010 and January 2011 for a subset of animals. Daily feeding behaviors for the first $2 \mathrm{~d}$ following calving were captured for 31 animals from continuous video recording using a wide-angle camera lens (Panasonic camera WV-CP504 and lens WVLZA61/2S, Panasonic Canada Inc., Mississauga, ON, Canada) connected to a recording system (GeoVision, UVS 1240E2, GeoVision Inc., USAVisionSys, Irvine, CA). Each animal's feeding behavior was analyzed by an individual blind to treatment and was defined as follows: (1) feeding visit: a visit consisted of the animal inserting her head past the head-gate in the manger up to her withers until the animal removed her head from the head-gate completely; and (2) total feeding time: the total amount of time (min) that the animal spent with her head though the head-gate up to the withers without being locked up in the head-gate for other reasons (e.g., for milking, for treatment, or for blood sampling). Total daily lying time and the number of transitions from standing to lying (or vice versa) were recorded using a 3-axis accelerometer (Hobo Pendant G loggers, Hoskin Scientific Ltd., Burnaby, BC, Canada; validation of this device can be found in Ledgerwood et al., 2010) attached to the right hind leg, on the day that each animal $(\mathrm{n}=38)$ entered the maternity pen, and recording at 1-min intervals. Lying behavior for the first $3 \mathrm{~d}$ following calving was analyzed.

\section{Statistical Analysis}

Because there were no existing data at the time of trial planning to inform expected production effects, sample size was estimated based on a combination of practicality of achieving the desired number of dystocic cows in a reasonable time from our research dairy and effects on important production parameters that were both detectable and relevant for the industry. Based on the year prior to the start of this study, we expected that 100 dystocic cows could be enrolled in this study, which would take between 12 and 24 mo depending on the incidence of dystocia. Data for the sample size calculations (mean $\pm \mathrm{SD}$ ) were based on previous studies conducted at the Elora Dairy Research Center. Sample size was therefore calculated for treatment groups (n $=48$ per group) based on detection of a difference of $2.4 \mathrm{~kg}$ of milk production with an SD of $3.6 \mathrm{~kg}$ and a difference of $0.50 \mathrm{~kg}$ of DMI with an SD of $0.75 \mathrm{~kg} / \mathrm{d}$ for the first 14 DIM with $95 \%$ confidence and $90 \%$ power.

Data were stored in a spreadsheet using Microsoft Office Excel (2010, Microsoft Corp., Redmond, WA) and all descriptive statistics and analyses were performed with Stata Intercooled 10.1 (StataCorp, College Station, TX). Mixed multivariable models were built including a random intercept for animals to account for multiple measurements being taken from each cow. Mixed linear regression models were for the outcomes of DMI, milk production, and serum metabolites (BHBA, NEFA, glucose, calcium, and haptoglobin). Linear regressions were used for the BW differences from calving to $60 \mathrm{~d}$ postcalving and for feeding behavior (visit numbers, total time at the feed bunk, and DMI). A logistic regression model was used for the bi- 
nary outcome of presence or absence of PVD. All tests were 2 -sided and significance was based on $\alpha<0.05$. For all outcomes, each predictor variable was screened individually and offered to the multivariable model if $P<0.20$. Variables were kept in the final model if $P$ $<0.05$ if they acted as a confounder or were part of a significant interaction term. A confounder variable was defined as a nonintervening variable whose inclusion in the model made a $20 \%$ or greater change in the coefficient of significant variables in the final model (Dohoo et al., 2003). Interactions between treatment and any significant covariates in the final model were tested. Linearity of predictors was assessed using a lowess (locally weighted scatterplot smoothing) curve for the continuous independent variables. If the linearity assumption was violated, the continuous outcome was transformed, or a quadratic term was included in the model, or the variable was categorized. To account for the curvilinear relationship between haptoglobin and time, a quadratic term was added to the model. The treatment variable was retained in all models, and time was forced into all mixed models.

We examined standardized residuals at the observation level to identify outliers for the linear and mixed linear regression models. For identification of outliers in the logistic model Pearson and deviance residuals were examined. In all random effect models we examined BLUPs for any outliers. Normality and homogeneity of variance were assessed for the observation-level standardized residuals for mixed linear models, and BLUPs were examined for the cow-level models. A Pearson goodness-of-fit test was performed for the regular logistic regression model for the PVD outcome.

\section{RESULTS}

\section{$B W$}

The mean $( \pm \mathrm{SD}) \mathrm{BW}$ before calving for heifers was $588 \mathrm{~kg} \pm 19$ and for cows was $699 \mathrm{~kg} \pm 21$. Treatment groups did not differ in BW change from calving to 60 DIM ( $\beta=2.5 \mathrm{~kg} ; P=0.80 ; 95 \%$ CI: $-17.6,22.7)$; however, we did observe a decrease in BW at 60 DIM compared with calving $(\beta=-34.4 \mathrm{~kg} ; P<0.001 ; 95 \%$ CI: -43.3 to -25.6$)$.

\section{Feed Intake and Milk Production Data}

Final regression models for DMI and milk production are summarized in Table 1. We observed no differences between meloxicam and placebo groups in DMI (overall mean $\pm \mathrm{SD}, 12 \pm 3 \mathrm{~kg} / \mathrm{d})$ or milk production $(22 \pm 8$ $\mathrm{kg} / \mathrm{d}$ ) over the first 14 DIM (Table 1). Both DMI and milk production increased over the first $14 \mathrm{~d}$ and heifers ate less and produced less milk than multiparous cows (Table 1). Animals that had retained fetal membranes produced less milk (Table 1) compared with animals that expelled their fetal membranes within the first $24 \mathrm{~h}$.

\section{Blood Analysis}

The meloxicam and placebo groups did not differ for any of the serum metabolites measured. Although we found time and parity effects for BHBA and NEFA, we found no effect of having retained fetal membranes. Cows with retained fetal membranes had higher haptoglobin concentrations $(\beta=0.25 \mathrm{~g} / \mathrm{L} ; P<0.05 ; 95 \%$ CI: $0.07,0.42)$.

Table 1. Mixed linear regression models of feed DMI from calving to $14 \mathrm{~d}$ postpartum and milk production from calving to $14 \mathrm{~d}$ postpartum for 100 Holstein cows with assisted calving randomly assigned to receive meloxicam $(0.5 \mathrm{mg} / \mathrm{kg}$ of BW once) or placebo approximately $24 \mathrm{~h}$ after calving

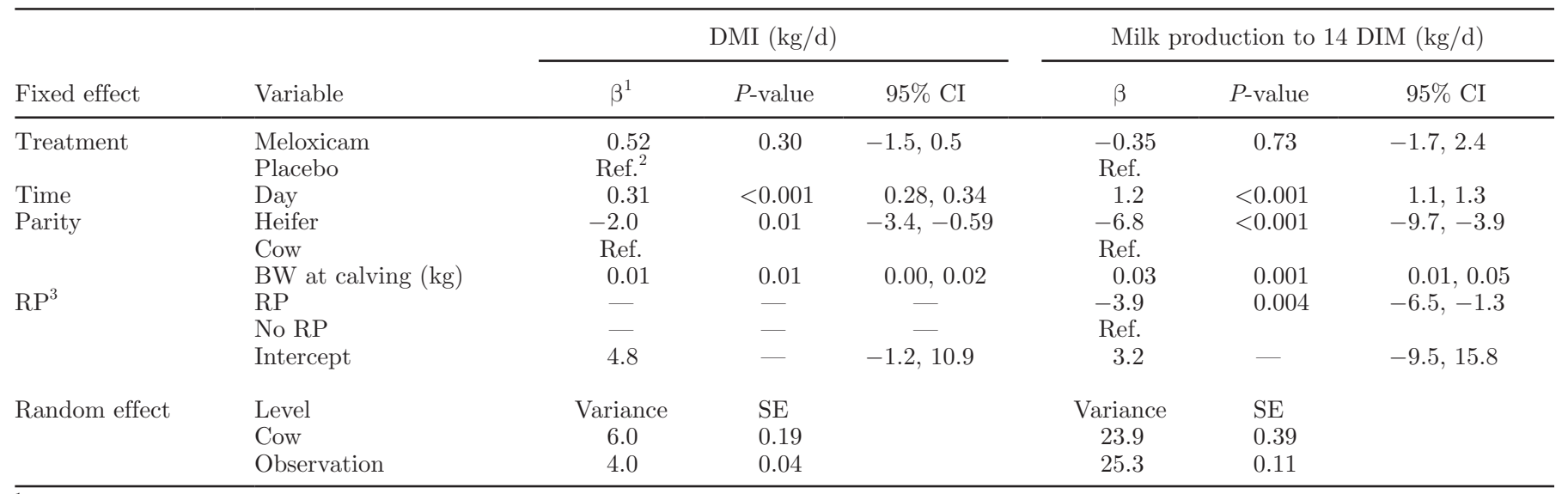

${ }^{1}$ Model coefficient.

${ }^{2}$ Referent.

${ }^{3} \mathrm{RP}=$ retained fetal membranes; $\mathrm{RP}$ covariate was not included in the DMI model because it was not significant. 


\section{Health Events}

Rectal temperature $\left(38.8^{\circ} \mathrm{C} \pm 0.61 \mathrm{SD}\right)$ did not differ $(P=0.84)$ over the first 10 DIM between treatment groups, and the odds of PVD did not differ between treatment groups at 30 to $36 \mathrm{DIM}$ (odds ratio $=1.2$; $P=0.83)$.

\section{Lying and Feeding Behavior}

Animals in the meloxicam group visited the feed bunk more often than those in the placebo group in the $24 \mathrm{~h}$ following treatment $(52 \pm 56 \mathrm{SD}$ and $28 \pm 13 \mathrm{SD}$, respectively; Table 2). Similarly, the total time spent feeding for meloxicam-treated animals was greater than for animals in the placebo group (223.4 min $\pm 112.8 \mathrm{SD}$ and $156.6 \mathrm{~min} \pm 73.0 \mathrm{SD}$, respectively; Table 2).

Total daily lying time (666.9 $\mathrm{min} \pm 182.5 \mathrm{SD})$, number of lying bouts (14.5 $\pm 5.2 \mathrm{SD})$, and average lying time per bout $(51.2 \mathrm{~min} \pm 21.4 \mathrm{SD})$ over the first 3 $\mathrm{d}$ postcalving were not different between treatment groups $(P>0.05)$.

\section{DISCUSSION}

The administration of meloxicam subcutaneously $24 \mathrm{~h}$ following assisted parturition in Holstein cows failed to improve DMI or milk production for the first 14 DIM. Treatment with NSAIDs has been shown to improve DMI in calves following dehorning or after developing diarrhea (Heinrich et al., 2010; Todd et al., 2010). In the study by Heinrich et al. (2010), calves treated with meloxicam following cautery dehorning had a tendency to consume more feed on $\mathrm{d} 1$ than on $\mathrm{d}$ 0 compared with control calves. In the study by Todd et al. (2010), meloxicam-treated calves that developed diarrhea and were enrolled after $10 \mathrm{~d}$ of age had greater odds of consuming all of the offered milk compared with placebo-treated calves of the same age with di- arrhea. Furthermore, calves treated with meloxicam began consuming starter ration earlier than placebotreated calves (Todd et al., 2010). On the other hand, oral meloxicam did not have any effect on DMI when given to beef calves that were castrated upon arrival at the feedlot compared with steers (Coetzee et al., 2012). Richards et al. (2009) did not find any effects of ketoprofen administration following calving on milk yield. Similarly, Duffield et al. (2009) and Shwartz et al. (2009) did not find any effect of flunixin meglumine on milk yield following calving. We also observed no treatment differences in metabolic indicators over the first $12 \mathrm{~d}$ or in the probability of PVD at 5 wk after calving.

The decision to treat at $24 \mathrm{~h}$ was made to ensure that meloxicam would not interfere with the prostaglandin response that may contribute to uterine contractions to expel fetal membranes (Horta, 1984). Duffield et al. (2009) reported an increase in the odds of having retained fetal membranes in animals that received flunixin meglumine approximately $2 \mathrm{~h}$ after calving. Similarly, Waelchli et al. (1999) reported a high probability of retained fetal membranes in cows administered flunixin meglumine following a caesarean section. On the other hand, treatment with 2 doses of ketoprofen, one immediately following calving and the second $24 \mathrm{~h}$ later, tended to reduce the incidence of retained fetal membranes in dairy cows (Richards et al., 2009). The potential for retained fetal membranes using an NSAID was the main reason why we waited $24 \mathrm{~h}$ before administering treatment. The NSAIDs act on cyclooxygenase enzymes COX-1 and COX-2, which in turn mediate prostaglandin production (Lees et al., 2004). Different NSAIDs have different affinities for COX-1 and COX-2, and the exact mechanism of NSAID on retained fetal membranes has not yet been determined. However, the 24-h delay in treatment administration may explain the lack of a treatment effect in the current study. Given

Table 2. Linear regression models for feeding behaviors and DMI for $24 \mathrm{~h}$ after injection controlling for baseline (the period from calving to time of treatment) for 31 animals with assisted calving and randomly assigned to receive meloxicam (0.5 $\mathrm{mg} / \mathrm{kg}$ of BW), or placebo, by subcutaneous injection approximately $24 \mathrm{~h}$ after calving

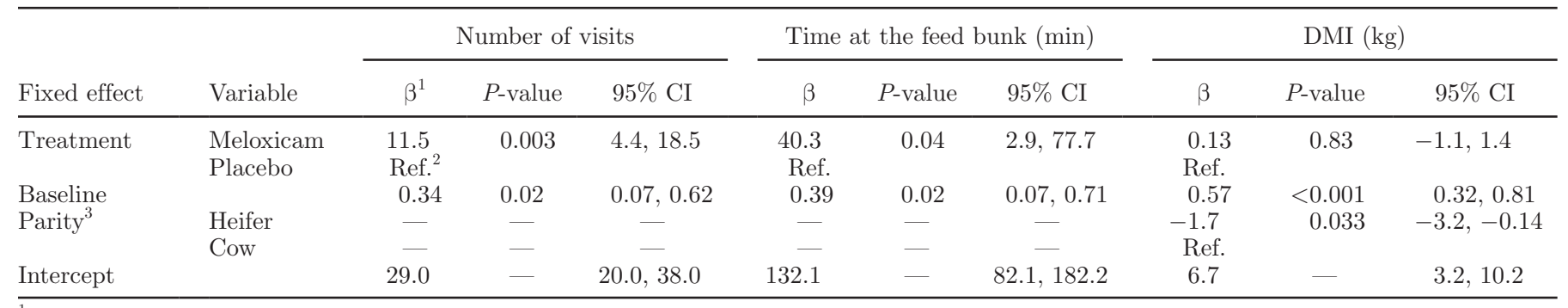

${ }^{1}$ Model coefficient.

${ }^{2}$ Referent.

${ }^{3}$ Parity covariate was not included in the number of visits and time at feed bunk models because it was not significant. 
that the placental separation process usually takes less than $6 \mathrm{~h}$ (van Werven et al., 1992), future investigations should consider administering meloxicam sooner (i.e., immediately following calving) to examine the risk of retained fetal membranes and ability to mitigate pain from calving.

Cows that received meloxicam spent more time at the manger on the day after treatment, although DMI did not differ in the $24 \mathrm{~h}$ after injection. The increased number of feeding visits and total time spent feeding for the first $24 \mathrm{~h}$ after calving in the meloxicam-treated animals suggests that administration of this NSAID could be alleviating some postcalving pain. Similarly, Theurer et al. (2012) reported that meloxicam-treated calves spent significantly more time with 1 foot from the grain bunk on $\mathrm{d} 2$ and 5 following dehorning compared with control calves, suggesting a potential positive effect of meloxicam on behavioral changes following a painful procedure. Other work has shown that lame cows at pasture grazed for shorter periods and had longer lying times than nonlame cows (Hassall et al., 1993; Winckler and Brill, 2004). Cows that received ketoprofen following left displaced abomasum surgery had greater odds of going to the feed bunk at fresh feed delivery for the first $3 \mathrm{~d}$ postsurgery compared with control animals based on observations by producers blinded to treatment (Newby et al., 2013). Improved DMI in dairy cows should improve milk yield, as intake and production are closely related, and potentially reduce the risk of disease (Drackley, 1999). Because this was not observed in the current study, the potential benefits may have been masked by the elevated endorphins still in the blood following parturition (Hydbring et al., 1999). Perhaps the cows that received meloxicam and spent more time at the feed bunk ate smaller but more frequent meals. Further research is needed to investigate the effects of longer term NSAID administration, or a higher dosage of NSAID, on feeding behavior because return to a more normal feeding behavior may improve rumen health with smaller and more frequent meals (Krause and Oetzel, 2006). The present study was done in a noncompetitive environment for the cows, where they had access to their own feed bunk. It would be interesting to investigate the potential benefits of meloxicam administration following calving on the feeding behavior of cows in a freestall system.

In the present study, the lack of effect of meloxicam on DMI, milk production, blood parameters, or lying behavior following an assisted calving could be due to insufficient attenuation of inflammation or pain or because the duration of effect of the meloxicam regimen used in this study was too short. Conversely, the differences in feeding behavior suggest that effects were produced and that further investigation of antiinflammatory treatment strategies is warranted.

\section{CONCLUSIONS}

This is one of the first studies to investigate the effects of administering the NSAID meloxicam following assisted calving. We observed no differences associated with treatment in DMI, milk production, or metabolic indicators. These outcomes may not have been sensitive to the effect of the drug or the dose regimen used in this study. We did observe short-term effects on feeding behavior that merit further investigation. We recommend future research to investigate different analgesic strategies (different dose, timing, and duration of meloxicam, and different drugs) to mitigate the effects of assisted calving.

\section{ACKNOWLEDGMENTS}

The authors thank the staff of the Elora and Ponsonby Dairy Research Centers. Funding was generously provided by Boehringer Ingelheim (Canada) Ltd. (Burlington, ON, Canada), Boehringer Ingelheim Animal Health GmbH (Ingelheim, Germany), a Natural Sciences and Engineering Research Council Industrial Post-Graduate Scholarship II to N.C.N., and the Ontario Ministry of Agriculture, Food and Rural Affairs (Guelph, ON, Canada).

\section{REFERENCES}

Atashi, H., A. R. Abdolmohammadi, A. Asaadi, A. Akhlaghi, M. Dadpasand, and Y. Jafari Ahangari. 2012. Using an incomplete gamma function to quantify the effect of dystocia on the lactation performance of Holstein dairy cows in Iran. J. Dairy Sci. 95:2718-2722.

Bionaz, M., E. Trevisi, L. Calamari, F. Librandi, A. Ferrari, and G. Bertoni. 2007. Plasma paraoxonase, health, inflammatory conditions, and liver function in transition dairy cows. J. Dairy Sci. 90:1740-1750.

Coetzee, J. F., L. N. Edwards, R. A. Mosher, N. M. Bello, A. M. O'Connor, B. Wang, B. KuKanich, and D. A. Blasi. 2012. Effect of oral meloxicam on health and performance of beef steers relative to bulls castrated on arrival at the feedlot. J. Anim. Sci. 90:1026-1039.

Dohoo, I., W. Martin, and H. Stryhn. 2003. Confounder bias: Analytic control and matching. Pages 30, 235-272 in Veterinary Epidemiologic Research. S. M. McPike, ed. AVC Inc., Charlottetown, Prince Edward Island, Canada.

Drackley, J. K. 1999. Biology of dairy cows during the transition period: The final frontier? J. Dairy Sci. 82:2259-2273.

Dubuc, J., T. F. Duffield, K. E. Leslie, J. S. Walton, and S. J. LeBlanc. 2010. Risk factors for postpartum uterine diseases in dairy cows. J. Dairy Sci. 93:5764-5771.

Duffield, T. F., H. Putnam-Dingwell, D. Weary, A. Skidmore, L. Neuder, W. Raphael, S. Millman, N. Newby, and K. E. Leslie. 2009. Effect of flunixin meglumine treatment following parturition on cow health and milk production. J. Dairy Sci. 92(E-Suppl. 1):118. (Abstr.) 
Geishauser, T., K. Leslie, D. Kelton, and T. Duffield. 1998. Evaluation of five cowside tests for use with milk to detect subclinical ketosis in dairy cows. J. Dairy Sci. 81:438-443.

Hassall, S. A., W. R. Ward, and R. D. Murray. 1993. Effects of lameness on the behaviour of cows during the summer. Vet. Rec. $132: 578-580$

Heinrich, A., T. F. Duffield, K. D. Lissemore, and S. T. Millman. 2010. The effects of meloxicam on behavior and pain sensitivity of dairy calves following cautery dehorning with a local anesthetic. J. Dairy Sci. 93:2450-2457.

Hewson, C. J., I. R. Dohoo, K. A. Lemke, and H. W. Barkema. 2007. Canadian veterinarians' use of analgesics in cattle, pigs, and horses in 2004-2005. Can. Vet. J. 48:155-164.

Horta, A. E. M. 1984. Efeitos das prostaglandinas E2 e F2 alpha sobre a retencao placentaria induzida pelo acetilsalicilato de lisina em vacas leiteiras; estudo da motilidade uterina. Zootechnia $33: 39-47$

Huxley, J. N., and H. R. Whay. 2006. Current attitudes of cattle practitioners to pain and the use of analgesics in cattle. Vet. Rec. 159:662-668.

Hydbring, E., A. Madej, E. MacDonal, G. Drugge-Boholm, B. Berglund, and K. Olsson. 1999. Hormonal changes during parturition in heifers and goats are related to the phases and severity of labour. J. Endocrinol. 160:75-85.

Krause, K. M., and G. R. Oetzel. 2006. Understanding and preventing subacute ruminal acidosis in dairy herds: A review. Anim. Feed Sci. Technol. 126:215-236.

Laven, R., P. Chambers, and K. Stafford. 2012. Using non-steroidal anti-inflammatory drugs around calving: Maximizing comfort, productivity and fertility. Vet. J. 192:8-12.

LeBlanc, S. J., T. F. Duffield, K. E. Leslie, K. G. Bateman, G. P. Keefe, J. S. Walton, and W. H. Johnson. 2002. Defining and diagnosing postpartum clinical endometritis and its impact on reproductive performance in dairy cows. J. Dairy Sci. 85:2223-2236.

Ledgerwood, D. N., C. Winkler, and C. B. Tucker. 2010. Evaluation of data loggers, sampling intervals, and editing techniques for measuring the lying behavior of dairy cattle. J. Dairy Sci. 93:5129-5139.

Lees, P., M. F. Landoni, J. Giraudel, and P. L. Toutain. 2004. Pharmacodynamics and pharmacokinetics of nonsteroidal anti-inflammatory drugs in species of veterinary interest. J. Vet. Pharmacol. Ther. 27:479-490.

Mee, J. F. 2008. Prevalence and risk factors for dystocia in dairy cattle. Vet. J. 176:93-101.

National Farm Animal Care Council. 2009. Health and welfare management. Pages 25-26 in Code of Practice for the Care and Handling of Dairy Cattle. NFACC, Ontario, Canada.
Newby, N. C., D. L. Pearl, S. J. LeBlanc, K. E. Leslie, M. A. G. von Keyserlingk, and T. F. Duffield. 2013. The effect of administering ketoprofen on the physiology and behavior of dairy cows following surgery to correct a left displaced abomasum. J. Dairy Sci 96:1511-1520. http://dx.doi.org/10.3168/jds.2012-5566.

NRC. 2001. Nutrient Requirements of Dairy Cattle. 7th ed. National Academy Press, Washington, DC.

Pinheiro Machado, L. C., J. F. Hurnik, and J. H. Burton. 1997. The effect of amniotic fluid ingestion on the nociception of cows. Physiol. Behav. 62:1339-1344.

Richards, B. D., D. H. Black, R. M. Christley, M. D. Royal, R. F Smith, and H. Dobson. 2009. Effects of the administration of ketoprofen at parturition on the milk yield and fertility of HolsteinFriesian cattle. Vet. Rec. 165:102-106.

Shwartz, G., K. L. Hill, M. J. VanBaale, and L. H. Baumgard. 2009 Effects of flunixin meglumine on pyrexia and bioenergetics variables in postparturient dairy cows. J. Dairy Sci. 92:1963-1970.

Skinner, J. G., R. A. L. Brown, and L. Roberts. 1991. Bovine haptoglobin response in clinically defined field conditions. Vet. Rec. 128:147-149.

Skinner, J. G., and L. Roberts. 1994. Haptoglobin as an indicator of infection in sheep. Vet. Rec. 134:33-36.

Tenhagen, B.-A., A. Helmbold, and W. Heuwieser. 2007. Effect of various degrees of dystocia in dairy cattle on calf viability, milk production, fertility and culling. J. Vet. Med. A Physiol. Pathol. Clin. Med. 54:98-102.

Theurer, M. E., B. J. White, J. F. Coetzee, L. N. Edwards, R. A. Mosher, and C. A. Cull. 2012. Assessment of behavioral changes associated with oral meloxicam administration at time of dehorning in calves using a remote triangulation device and accelerometers. BMC Vet. Res. 8:48-55.

Todd, C. G., S. T. Millman, D. R. McKnight, T. F. Duffield, and K. E. Leslie. 2010. Nonsteroidal anti-inflammatory drug therapy for neonatal calf diarrhea complex: Effects on calf performance. J. Anim. Sci. 88:2019-2028

van Werven, T., Y. H. Schukken, J. Lloyd, A. Brand, H. Tj. Heeringa, and M. Shea. 1992. The effects of duration of retained placenta on reproduction, milk production, postpartum disease and culling rate. Theriogenology 37:1191-1203.

Waelchli, R. O., R. Thun, and H. Stocker. 1999. Effect of flunixin meglumine on placental expulsion in dairy cattle after a caesarean. Vet. Rec. 144:702-703.

Winckler, C., and G. Brill. 2004. Lameness prevalence and behavioura traits in cubicle housed dairy herds - A field study. Page 160 in Proc. 13th Int. Symp., 5th Conf. Lameness in Ruminants, Maribor, Slovenia. 